\title{
Analysis on Economic Impact of Flood Control and Disaster Mitigation--A Case Study of Togtoh County
}

\author{
Baotana $^{1}$, Buren ${ }^{2}$, Xiaojun Huang ${ }^{3}$ \\ 1School of Geography, Inner Mongolia Normal University, Hohhot 010022, China \\ 2Institute of Natural disaster prevention and Control, Inner Mongolia Normal University, Hohhot \\ 010022, China
}

3Key Laboratory of Remote Sensing\&Geography Information System, Inner Mongolia Normal

University, Hohhot 010022, China

\section{防洪减灾对经济影响的分析一以托克托县为例}

\author{
包塔娜 ${ }^{1}$, 布仁 ${ }^{2}$, 黄晓君 ${ }^{3}$ \\ 1 内蒙古师范大学地理科学学院, 内蒙古 呼和浩特 010022 , 中国 \\ 2 内蒙古师范大学自然灾害防治研究所, 内蒙古 呼和浩特 010022, 中国 \\ 3 内蒙古自治区遥感与地理信息系统重点实验室, 内蒙古 呼和浩特 010022 , 中国
}

\begin{abstract}
Our country is one of the countries which are affected by natural disasters most in the world. Every year, disasters cause huge losses to national economy and people's living. Since it enters into 1960s, rainstorms, flood and waterlogging have become major disasters which affect our country's social and economic development. The paper analyzes many years' change of agricultural acreage, grain yield, peasant income and GDP data of Togtoh county. And it concludes that various water-and-soil conservation measures play a huge role in flood control and disaster mitigation and economic development, etc through thirty years' key harnessing of flood control and disaster mitigation in Togtoh county, which not only improves production condition, accelerates farmers and herdsmen to shake off poverty and become prosperous, but also sets an example in sustainable development.
\end{abstract}

Keywords: flood control and disaster mitigation economic development Togtoh county

\section{摘要}

我国是世界上受自然灾害影响最大的国家之 一，每年灾害对国民经济和人民生活造成巨大 的损失。进入 20 世纪 60 年代以来, 暴雨洪涝 灾害已成为影响我国社会经济发展的重大灾 种。本文对托克托县多年耕地面积的变化、粮 食产量、农民收入以及 GDP 数据进行分析, 得 出托克托县经过 30 年防洪减灾重点治理, 各 项水土保持措施在防洪减灾和经济发展等方 面发挥了巨大作用, 不但改善了生产条件, 快 了农牧民脱贫致富, 而且在可持续发展中作出 了榜样。

关键字: 防洪减灾 经济发展 托克托县

1. 引言

随着经济融合度增大, 人与自然之间的关 系越来越密切, 人类改造自然的强度越来越大, 灾害的发生, 将对经济系统进行冲击, 经济损 


\section{Risk Analysis and Crisis Response in Big Data Era (RAC-16)}

失呈上升趋势。我国是世界上受自然灾害影响 最大的国家之一，每年灾害对国民经济和人民 生活造成巨大的损失。进入 20 世纪60年代以来, 我国洪涝灾害所造成的损失比重明显增加, 并 且有持续增长趋势, 暴雨洪涝灾害已成为影响 我国社会经济发展的重大灾种。托克托县隶属 于内蒙古自治区首府呼和浩特市。肥沃的黄河 两岸，早在 5000 多年以前就已是猎人、牧人和 农人的出没之地。但是清代以后, 人类掠夺式 的开发利用打破了原有的生态平衡, 托克托县 境内河流由 “利河” 变为 “害河”, 影响了素 有 “众水归托”之称的托克托县的发展。这不 仅加速了水土流失，而且干扰了黄河中下游的 水沙运行规律, 湖泊湮没, 导致河流泛滥危害 无穷, 以致河患不断发生。

近年来国内外学术界比较关注自然灾害 及其对社会经济影响的研究, 20 世纪 50 年代 以后, 灾害经济研究开始正式步入各国经济学 家视野，最具代表性的研究成果就是 Brannen （1954）对 1953 年德克萨斯经历的大灾难中 涉及的经济问题进行了相关研究 ${ }^{[1]}$ 。Benseon (2003) 发现灾害发生频繁的国家增长率要低 于灾害发生较少的国家 ${ }^{[2]}$ 。Noy（2009）研究 了灾害对多国的宏观经济影响, 发现灾害对农 业部门打击最大, 会使发展中国家的 GDP 下降 多个百分点 ${ }^{[3]}$ 。

相对于发达国家而言, 我国灾害研究起步 较晚。20世纪80年代, 著名经济学家于光远在 中国首次明确提出研究灾害经济学。卜风贤、 吕卓民将自然灾害与农业生产联系起来, 揭示 了当时农业开发的必然性 ${ }^{[4-5]}$; 刘雯将自然灾 害的历史演变和区域社会经济的历史变迁结 合起来研究了二者之间的互动关系 ${ }^{[6]}$ 。内蒙古 对防洪减灾的研究有布仁介绍了近几十年内 蒙古突发性洪涝灾害孕灾环境以及提出了相 应的防治措施 ${ }^{[7]}$; 间新光对于洪水的成因及防 汛作出了探讨 ${ }^{[8]}$ 。

本文通过托克托县防洪减灾的水利建设, 对多年耕地面积的变化、粮食产量、农民收入 以及 GDP 数据进行分析, 以托克托县为研究对 象, 来表明防洪减灾对经济发展的影响。

\section{2. 研究区及其洪灾概况}

（1）地形地貌

托克托县是呼和浩特地区有悠久历史的 一个县, 它位于土默川平原西南部，总面积 1416. 8 平方公里, 海拔高度在 $988^{-}-1277 \mathrm{~m}$, 辖 5 镇、13 个居委会、120 个村委会。地理坐 标在东经 $111^{\circ} 2^{\prime} 30^{\prime \prime}-111^{\circ} 32^{\prime} 21^{\prime \prime}$ 、北 纬 $40^{\circ} 5^{\prime} 55^{\prime \prime}-40^{\circ} 35^{\prime} 15^{\prime \prime}$ ，地势为东南 高而西北和西南低, 其地貌为东南高, 西北、 西南低, 有丘陵地形过渡到宽广的平原地形, 可分为五类：丘陵区、山前倾斜平原、胡积台 地、宽谷洼地和冲积平原。主要灌溉的河流有 黄河, 大黑河、什拉乌素河、沙河、宝贝河和 银号河。托克托县耕地绝大部分处于冲积湖平 原上，地势低平，土壤质地适中，土壤肥力 也较高, 有利于耕作业活动。

\section{（2）气候水文}

托克托县属于温带大陆性气候, 四季分明, 光热条件较好, 能够满足一年一熟的农作物 生长要求，气候资源利用潜力很大, 年平均日 照时数为 $3035 \mathrm{~h}$, 年平均气温 $6.7^{\circ} \mathrm{C}$, 无霜期 平均为 131 天。多年平均降水量为 $361 \mathrm{~mm}$, 其 中 6 9 月降水占 65- 82\%, 蒸发量为 $1936 \mathrm{~mm}$ 。 黄河流经县境 $37.5 \mathrm{~km}$, 全县水资源总量较丰 富, 约有 4.53 亿 $\mathrm{m}^{3}$, 其中黄河的年均径流 量为 4.14 亿 $\mathrm{m}^{3}$ ，占全县水资源总量的 $91.6 \%$ 以上，有利于灌溉农业的发展。

\section{(3) 社会经济}

托克托县是以种植业为主, 农业、工业和 服务业相结合，多种经营的综合性农业县。农 业发展历史悠久, 农业经济基础条件较好, 农 业集约经营程度相对较高, 社会经济发展水平 较高。地处呼、包、鄂 “金三角” 开发区腹地, 是首府 “一核双圈一体化” 战略重点发展区。 2014 年托克托县入选中国中小城市综合实力 百强县市第 57 位和中国最具投资潜力中小城 市百强县市第 47 位。目前, 托克托工业园区 是自治区 20 个重点工业园区之一, 是托克托 县经济发展的最大平台。

\section{（4）研究区洪灾概况}

托克托县自然灾害频繁，主要有干旱、洪 涝、霜冻、大风和冰雹等, 尤以干旱和洪涝灾 害较普遍。洪涝灾害限制了本县农业的发展, 成为农业优质、高产、稳定发展的主要障碍因 
Risk Analysis and Crisis Response in Big Data Era (RAC-16)

素。托克托素有 “众水归托” 之称, 河流除黄 河外，多系季节性河流，天旱时河床干涸，雨 涝时洪水下泄, 最易造成灾害。由于清代之后, 大青山森林的砍伐殆尽, 再加上草场变为农田, 积史籍记载洪涝灾害自清代起逐渐增多（表 1-1), 当时也曾设想修筑河堤, 以防洪水淹没 村庄和农田, 只因战事频繁, 兵荒马乱, 最终 未能实现，从而造成洪水逐年泛滥。
由此水利成为水害, 洪水虽为天灾, 但也不乏 人为的因素。在河道内是荒种植, 使河床逐年 提高, 由宽变窄, 就此给安全度汛埋下了较大 的隐患, 近百年来水土流失极为严重, 因此洪 水灾害有增无减。新中国成立之后, 托克托县 多次出现洪灾, 面对这种危机, 地方政府对防 洪减灾的问题，进行了艰苦地探索。

表 1-1: 托克托县历年洪灾沿革

\begin{tabular}{|c|c|c|}
\hline $\begin{array}{l}\text { 清道光三十年 } \\
\text { (公元 } 1850 \text { 年) 秋 }\end{array}$ & 洪灾 & $\begin{array}{l}\text { 大雨不止, 黄河水涨, 托克托县河口镇堤防溃决, 民房、商店被冲毁, 南滩一带 } \\
\text { 尤甚。灾后, 市况大衰。 }\end{array}$ \\
\hline $\begin{array}{l}\text { 清咸丰六年 } \\
\text { (公元 } 1856 \text { 年)九月 }\end{array}$ & 洪灾 & 托克托、归化、萨拉齐三厅露雨为灾，大水淹没田禾。灾重，告饥。 \\
\hline $\begin{array}{l}\text { 清光绪二年 } \\
\text { (公元 } 1876 \text { 年) }\end{array}$ & 洪灾 & 和林格尔、清水河、托克托各厅, 上年灾䉼无收, 春夏复遭早、水等灾害。 \\
\hline $\begin{array}{l}\text { 清光绪三十年 } \\
\text { ( 公元 } 1904 \text { 年)秋 }\end{array}$ & 洪灾 & $\begin{array}{l}\text { 托城、河口镇阴雨连绵, 黄河水涨, 淹没成灾。大小 (黑河) 淹没七星湖村基达 } \\
\text { 四尺之谱, 平地水深丈余, 经旬不退。 }\end{array}$ \\
\hline $\begin{array}{l}\text { 民国元年 } \\
\text { (公元 } 1912 \text { 年) 八月 }\end{array}$ & 洪灾 & 托县中滩等村被水成灾 \\
\hline $\begin{array}{l}\text { 民国 } 18 \text { 年 } \\
\text { (公元 } 1929 \text { 年) }\end{array}$ & 洪灾 & $\begin{array}{l}\text { 立秋后, 大雨五日夜, 山洪暴发, 黄河亦决口。归绥、托克托、萨拉齐等十县, } \\
\text { 悉成泽国, 晚禾淹没, 田庐冲毁无算。 }\end{array}$ \\
\hline $\begin{array}{l}\text { 民国三十五年 } \\
\text { (公元 } 1946 \text { 年) 秋 }\end{array}$ & 洪灾 & 托县山洪暴发, 黑河猛涨, 黄河倒扬, 个乡村均被淹成灾。 \\
\hline 公元 1952 年七月 & 洪灾 & $\begin{array}{l}\text { 大黑河洪水泛滥, 托县十一村被灾。冲毁房屋 } 27 \text { 间, 粮田 } 6.7 \text { 万亩, 被灾人口 } \\
13329 \text { 人。人民政府赈灾民粮食 } 59 \text { 万斤。 }\end{array}$ \\
\hline 公元 1958 年秋 & 洪灾 & $\begin{array}{l}\text { 黑河猛涨出岸，托县五公社被毁民房和粮田甚重。赈灾民口粮及衣物计人民币 } \\
\text { 13. } 36 \text { 万元。 }\end{array}$ \\
\hline 公元 1959 年秋 & 洪灾 & $\begin{array}{l}\text { 山洪暴发, 大黑河水涨出岸, 禾稼全部淹没, 重灾面积达一万四千亩, 房屋倒塌 } \\
\text { 五十九间, 牲口死亡十几头。 }\end{array}$ \\
\hline 公元 1961 年秋 & 洪灾 & 大黑河泛滥, 黑河两岸重灾面积达二万七千亩, 房屋倒塌一百七十二间。 \\
\hline 公元 1967 年秋 & 洪灾 & $\begin{array}{l}\text { 黄河水涨, 进入托克托县流量为 } 5300 \text { 秒立米, 逆水黑河, 淹没农田七千三百亩, } \\
\text { 房屋倒塌五十一间。 }\end{array}$ \\
\hline 公元 1971 年秋 & 洪灾 & 托县东山降暴雨, 山洪暴发, 黑城大队被冲毁房屋百十多间, 牲畜死伤几十头。 \\
\hline 公元 1979 年秋 & 洪灾 & $\begin{array}{l}\text { 黑河暴涨泛滥, 古城、乃只盖、五申、四滩四公社 } 17.55 \text { 万亩粮田被淹, 冲毁房 } \\
\text { 屋 } 198 \text { 间, 成灾人口 } 4.5 \text { 万人。 }\end{array}$ \\
\hline 公元 1981 年秋 & 洪灾 & $\begin{array}{l}\text { 大黑哥、什拉乌素河上游降暴雨, 河水出岸。五个公社淹没农田 } 74497 \text { 万亩, 房 } \\
\text { 屋倒塌 } 618 \text { 间, 成灾人口 } 24685 \text { 人。 }\end{array}$ \\
\hline 公元 1987 年秋 & 洪灾 & $\begin{array}{l}\text { 乌兰察布盟、伊克昭盟和呼和浩特、包头二市, 连降大雨, 大黑河、宝贝河、什 } \\
\text { 拉乌素河的堤坝多处决口, 托克托县有 } 64 \text { 个村庄被洪水围困, } 2639 \text { 间住房被冲 } \\
\text { 倒, 大批灾民无家可归 }\end{array}$ \\
\hline 公元 1994 年秋 & 洪灾 & $\begin{array}{l}\text { 因上游流域突降大暴雨, 大黑河出现了流量为 } 1450 \text { 秒立米的大洪峰, 洪水总量 } \\
\text { 约 } 4000 \text { 万立米。沿河两岸的郊区、土左旗、托县分别在旗县区主要领导同志带 } \\
\text { 领下修堤抢险。 }\end{array}$ \\
\hline
\end{tabular}

资料来源: 《托克托县志》 
Risk Analysis and Crisis Response in Big Data Era (RAC-16)

\section{3. 数据资料与研究方法}

3.1 数据资料

本文利用的数据资料有: 《托克托县志》 中的自然灾害数据; 2000 年 -2015 年《内蒙古 统计年鉴》中的耕地面积、粮食产量、国民生 产总值、第一产业产值以及农民收入等数据。 3.2 研究方法

\section{(1) 文献资料检索法}

通过查阅和收集有关防洪减灾与区域经 济相关性研究的国内外相关文献, 系统收集有 关统计资料, 并对其进行分析与借鉴, 作为论 文写作的重要依据。同时收集历年粮食产量变 更数据、耕地面积变更数据和影响区域经济发 展相关资料。

(2) 数理统计方法

用于防洪减灾和经济发展变化规律、农业 与国民经济发展相关分析等方面的研究。主要 有: 运用农产量相对变化率和耕地面积变化率 以及农民收入变化率研究研究区经济发展的
动态变化特征。分析防洪减灾对经济的影响程 度及其水利设施对耕地变化特点。

\section{4. 研究结果与分析}

4.1 洪涝灾害的发生对托克托县人民生活条件 的影响

洪涝灾害会恶化人们的生活条件, 主要表 现为对人们原有的住房、饮水等生活必需品造 成破坏, 同时, 生活条件的恶化还将造成日常 生活产生的废物、污水难以得到正常清理, 使 得疾病和传染病的发生概率大大增加, 进而激 化社会矛盾, 影响社会稳定。洪涝灾害发生时, 通常会对农牧渔业、工业交通运输业和水利设 施造成直接破坏, 导致农田受灾、农产品产量 下降; 交通运输中断; 电力通信中断; 水利设 施毁坏等直接后果, 严重影响着国民经济的正 常运行和可持续发展。托克托县洪灾会造成大 量的农田淹没、房屋倒塌, 大量灾民无家可归, 从而影响了当地经济的发展, 使粮食产量减少, 农民收入下降，如表 3-1 所示。

表 3-1：1959 年-1990 年全县洪灾年间与非洪灾年间粮食产量及收入对比统计表 单位: 总产量 (吨)、收入 (万元)

\begin{tabular}{|c|c|c|c|}
\hline 年度 & 粮食产量 & $\begin{array}{l}\text { 农民人均纯收入 } \\
\text { (元) }\end{array}$ & 总收入 \\
\hline 1959（洪灾） & 29023 & 32 & 703 \\
\hline 1960 & 30887 & 37 & 745 \\
\hline 1961（洪灾） & 21565 & 27 & 436 \\
\hline 1963 & 25691 & 27 & 615 \\
\hline 1966 & 35171 & 44 & 972 \\
\hline 1967（洪灾） & 34960 & 54 & 1115 \\
\hline 1975 & 61709 & 63 & 1945 \\
\hline 1979 （洪灾） & 40099 & 42 & 1575 \\
\hline 1981（洪灾） & 46933 & 248 & 1506 \\
\hline 1982 & 58615 & 303 & 2646 \\
\hline 1984 & 54326 & 305 & 4233 \\
\hline 1987（洪灾） & 26987 & 287 & 4329 \\
\hline 1989 & 54666 & 432 & 7657 \\
\hline 1990 & 67390 & 527 & 10506 \\
\hline
\end{tabular}

资料来源: 《托克托县志》

4.2 防洪减灾政策促进了托克托县经济的发展

毛主席曾经说过: “水利是农业的命脉”, 面对水 患, 新中国成立后, 党和政府非常重视这一事业。1954
年首先对黑河、沙河两个自流灌溉区进行了水利制度 的改革，废除了旧章程，建立了群众性的水利管理委 员会，在黄河岸边、大黑河岸边及什拉乌素河岸边等 堤防所相继成立。1950 年绥远省水利局长带领工程 
Risk Analysis and Crisis Response in Big Data Era (RAC-16)

技术人员到现场勘查, 为黄河左岸大堤选线, 之后 1998 年黄河段大堤加固工程被列入国家大江大河险 工段一期治理工程, 以确保沿河农田的浇灌。新中国 成立 60 来年, 托克托县人民政府按照 “建重于防, 防重于抢” 的防汛工作方针, 组织全县人民坚持不解 地治理河流水系, 形成了以黄河、大黑河堤防为主的 防洪体系, 同时每年在防汛期到来之前, 对防凌防汛 工作都要做出具体安排, 付诸实施。1992 年后, 堤 防所统一更名为河道管理段, 防汛部门成立了水政监 察大队防汛执法中队, 加强了防汛执法队伍的建设, 堤防管理和堤防建设事业有了较大的发展。自 50 年 代开始托克托县便开始治理水土流失, 70 年代逐步 实行生物措施和工程措施相结合的治理方法, 到了 80 年代，贯彻执行 “防治并重、治管结合、因地制
宜、全面规划、综合治理、兴利除害” 的水保方针。 从 50 年代到 2000 年, 国家共为托克托县投入水土保 持事业经费 520 多万元, 累计治理面积 225560 公顷。 综合治理控制了水土流失, 改善了生态环境, 提高了 土壤肥力, 减轻了自然灾害, 促进了经济发展, 提高 了当地人民的生活水平。改革开放以来坚持把发展作 为第一要务, 特别是进入九十年代中期, 托克托县经 济呈加速发展的态势。群众说是党的政策和通过水土 保持使他们摆脱了贫困、落后和愚昧, 走向了文明与 富裕。国内生产总值是反映整个地区国民经济发展总 水平、总规模的总量指标, 下面 (表 3-2) 以国内生 产总值指标对托克托县近 50 年的经济发展水平进行 总体的差异对比。

表 3-2 托克托县近 50 年人口与 GDP 发展变化对比表（单位: 万元）

\begin{tabular}{lcc}
\hline 年份 & 年末总人口 (万人) & 生产总值 $($ 万元 $)$ \\
\hline 1965 & 11.54 & 986 \\
1970 & 12.76 & 1516 \\
1975 & 14.16 & 2356 \\
1980 & 15.50 & 2456 \\
1985 & 16.53 & 4960 \\
1990 & 17.37 & 11823 \\
1995 & 18.64 & 71018 \\
2000 & 19.03 & 129667 \\
2005 & 19,59 & 651088 \\
2010 & 20.58 & 1729310 \\
\hline
\end{tabular}

资料来源：1965-2010 年《内蒙古统计年鉴》

\section{3 完善的防洪减灾工程对托克托县耕地变化与经 济的影响}

早在民国期间分别于公元 1926 年、1930 年和 1935 年有三次大黑河水利工程计划, 三次治理计划 都呈现出 “统筹规划” 的思想, 但每次都要面临政局 动荡、灾荒连年、资金匮乏的尴尤境遇，使其无法开 展工作。由于地理位置的特殊, 降雨几乎都流经托克 托县汇入黄河, 从而加大了防汛抗洪工作的难度。新 中国成立后，依据大黑河下游未建护堤、干流淤塞， 且当地农民在河滩内大量垦种, 若遇洪水乃必然成灾。 对于河道的治理主要有黄河堤防工程和什四份子控 导 (护岸) 工程。(1) 黄河堤防工程: 1950 年由省 水利局修防处为黄河左岸大堤定线, 施工段从原萨拉 齐县边界起至上沙拉湖滩村东南, 长 2.83 公里, 该 工程竣工后又动工修建大黑河西堤的黄河附堤, 完成 土方 38 万多立方米, 后又逐年修堤筑坝, 河堤互连。 1967 年在黄河出现了 5300 立方米每秒洪峰的情况下,
堤坝安然无事, 均安全下泄, 保证了下游的粮食丰收。 1998 年黄河段大堤加固工程被列入国家大江大河险 工段一期治理工程。按照设计要求加固堤防标准为二 级 (顶宽 6 米、内外边坡 $1: 3$ 、水位超高 1.8 米), 同时按照四级公路标准, 铺设宽 4 米, 厚 8 厘米的砂 石料路面, 并在黄河大堤上建修钢筋混凝土涵闸 12 处, 以确保沿河农田浇灌, 总投资 213 万元。(2) 什 四份子控导 (护岸) 工程: 1976 年, 柳林滩、什四 份子等村划入托克托县后, 县境的黄河大堤正堤增长 至 25 公里, 有多处险工段。经过 1984-1998 年的维 护、治理, 共建成柴石坝垛 65 座, 整治河道 2120 米, 完成顶宽 5 米、外边坡 1:3 的护围坝 1000 米和 延长护岸 1000 米的工程, 加固连坝格堤 2120 米。总 投资为 313.509 万, 其中国家投资 240 万元, 市、县 地方投资 73.509 万。

常言道: “水火无情”, 在 1987 年自治区人民政 府召开了抗灾救灾会议之后托克托县水利事业有了 很大发展。新建一级扬水站一处, 二级扬水站三处, 
Risk Analysis and Crisis Response in Big Data Era (RAC-16)

三级扬水站四处; 修通干渠 16 条, 总长达 232 公里。 支渠 44 条, 全长 156 公里, 可防御 10 年一遇洪水, 沿大黑河干流及主要支流的下游两岸, 建有 20 余处 万亩以上的灌区, 沿黄河大堤还修了镫口、团结、托 克托等 4 处扬水工程。两岸防洪大堤距离在 3000 米 左右, 主河道宽 500 米上下, 在堤坝上面由砂石加固。 当涨势达到 1600 立方米每秒的时候才会将两岸的种 植产物淹没, 当地专门设有测量黄河流量和水位的船 只, 保证防汛工作的顺利实施。

据调查, 通过治理改善了生产条件方便了群众的 生产生活, 促进了城乡结合, 加快了经济发展。从
2000 年开始, 托克托县累计投入上亿元设施建设, 新建、续建、修整各种农水利设施, 全县基本实现了 保灌。已形成 “以黄河灌溉为主, 机井灌溉为辅” 的 灌溉体系, 可基本实现旱涝保收, 在全市第一个实现 了农水利化目标, 群众经济收入的增加, 促进了生活 条件的改善, 坚持 “两手抓、两促进”, 一手抓防汛 减灾重建, 一手抓经济社会发展, 奋力夺取抗洪救灾 和经济发展的双胜利。防洪减灾工程有效保护了耕地 面积不受损失的同时也促进了全县第一产业的发展, 加快农牧民脱贫致富的步伐, 如图 3-3-1、3-3-2 所 示。

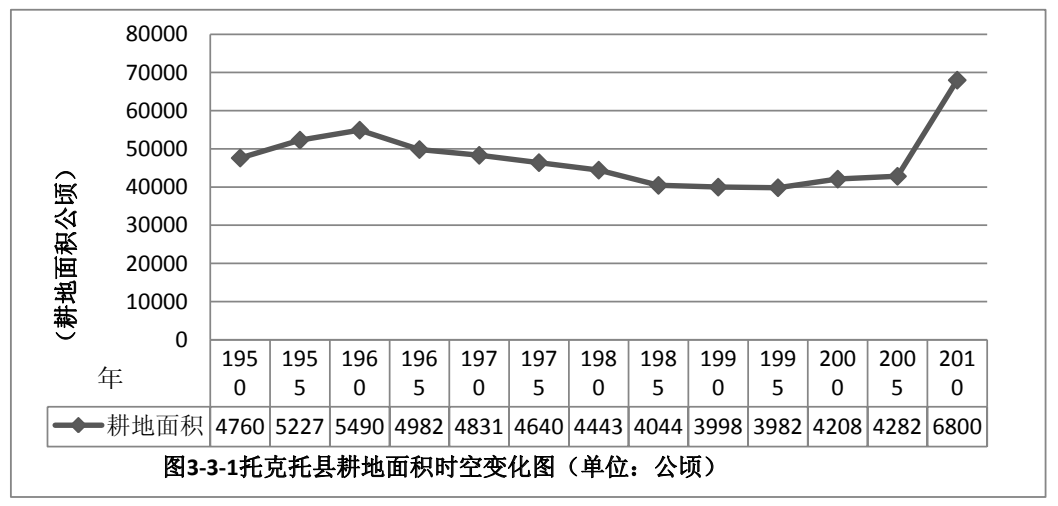

资料来源: 1950-2010 年《内蒙古统计年鉴》

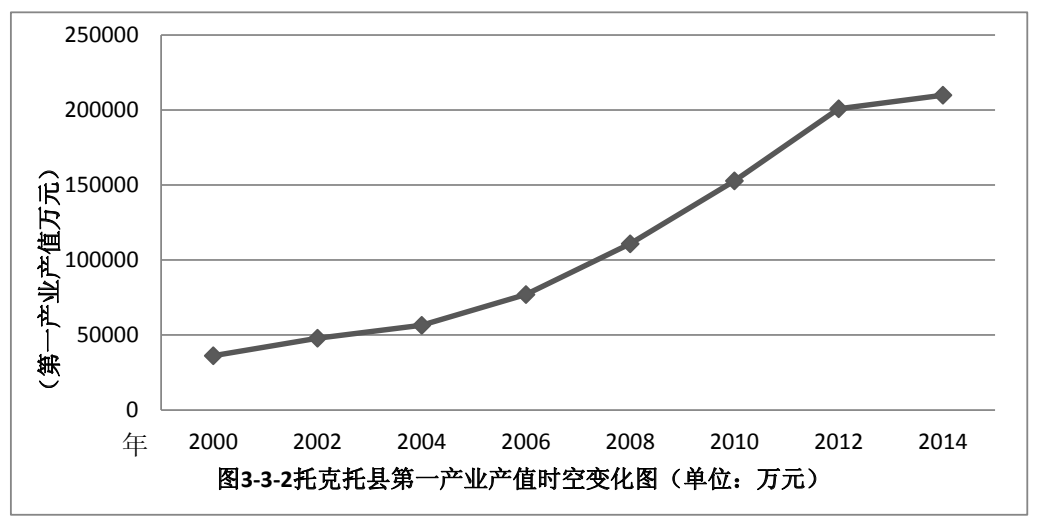

资料来源: 2000-2014 年《内蒙古统计年鉴》

\section{5. 结束语}

新中国成立后，托克托县将工作重心从 前期的全力以赴抓防汛减灾转到防汛与重点
工作推进两不误上来, 一方面健全巡查机制, 紧抓以公路、河堤为主的基础设施抢修恢复, 防止下一轮灾害; 密切关注汛期天气变化, 加 
Risk Analysis and Crisis Response in Big Data Era (RAC-16)

强巡查, 确保一旦发生汗情, 能及时了解雨情、 水情、险情、灾情等信息, 及时进行报告并迅 速采取应对措施。保障防汛抗洪救灾工作顺利 进行; 坚持以人为本, 做好疫病防治工作, 组 织群众积极开展生产自救, 全方位帮助受灾群 众增加收入。另一方面, 加快推进投资促进工 作, 加快在建项目建设进度, 进一步加快恢复 农业生产, 重点抓好设施农业发展, 提高农业 效益和抗灾能力, 确保全县经济发展不受影响。 多年来, 在科学规划的指导下, 坚持集中规模 的科学治理, 形成了科学的防治和开发体系, 有效地控制了水土流失, 极大的提高了防洪抗 灾能力。今后, 对河道的治理还需进一步加强, 一定要常抓不解, 只利用好大托克托县的水资 源, 真正做到防洪用洪, 才能保证人民的财产 不受损失，并保证其农牧业的连年丰收。

\section{参考文献}

[1] 卜风贤.西汉时期西北地区农业开发的自 然灾害背景.干旱区自然与环境,2008，22 (10): 83-86.

[2] T.R. Brannen. Economic aspects of the Waco Texas Diasater of May 11, 1953. Department of Sociology, University of Texas, Research Report, 1954
[3] 吕卓民.自然灾害与农业生产.西北大学学 报,2008,38(2):323-328

[4] C. Benson. The economy-wide impact of natural disasters in developing countries, [Doctoral dissertation, University of London].London: University of London, 2003

[5] Noy I.The macroeconomic consequences of disasters.Journal of Development Economics, 2009, 88(2):221-231

[6] 刘雯.历史时期青海地区自然灾害与区域 社会经济发展研究. 西北农林科技大 学, 2009 .

[7] 间新光. 内蒙古 1998 年特大洪水成因及今 后防汛工作的探讨. 东北水利水电, 1994(4): 17-18.

[8]《托克托县志》.[S]托克托县志编写委员 会.1984

[9] 1965-2015《内蒙古统计年鉴》.[S]内蒙古 统计局

[10] W. Wang, C. Zhou, X. Du. The research of a hail risk evaluation under imperfect information. Journal of Risk Analysis and Crisis Response, 2011, 1(2):133-141. 